INPATIENT CARE

FOR CEREBRO-

VASCULAR DISEASE

\title{
A descriptive study of inpatient admissions for cerebrovascular disease at a tertiary hospital in KwaZulu-Natal, South Africa
}

\section{Yoshan Moodley and Jamila Kathoon Adam}

Durban University of Technology, Durban, KwaZulu-Natal, South Africa

Address for correspondence:

Dr Yoshan Moodley

Directorate for Research and Postgraduate Support

Durban University of Technology

PO Box 1334

Durban

4000

South Africa

Email:

YoshanM@dut.ac.za

\section{INTRODUCTION}

The American Association of Neurological Surgeons broadly defines cerebrovascular disease (CVD) as a "disorder in which an area of the brain is temporarily or permanently affected by ischaemia or bleeding and one or more of the cerebral blood vessels are involved in the pathological process." (I) Thus, the definition of CVD encompasses stroke, carotid stenosis, vertebral stenosis, intracranial stenosis, aneurysms, and vascular malformations. (1) Globally, CVDs represent an important cause of morbidity and mortality. (2) Although the burden of disease attributed to CVDs has traditionally been higher in industrialised nations, recent trends analyses suggest an increasing burden of CVDs in developing countries, including South Africa. ${ }^{(2)}$ In fact, CVDs are now ranked the second most important cause of death in the country. ${ }^{(3)}$ The steep increase in CVD-associated morbidity and mortality is likely attributable to rapid urbanisation and adoption of Westernised lifestyles by South Africans, coupled with a concomitant increase in CVD risk factors in the general population. ${ }^{(4,5)}$

CVD is associated with considerable resource utilisation at South African public hospitals. An analysis of 195 stroke patients admitted to the GF Jooste Hospital in Cape Town during 200I - 2002 revealed that patients stayed an average of 6.5 - 10.4 days in hospital depending on whether they were admitted to a general ward or a specialist stroke unit.(6)

\section{ABSTRACT}

Background: We sought to provide a descriptive report of inpatient admissions for cerebrovascular disease (CVD) at a tertiary hospital in KwaZulu-Natal, South Africa.

Methods: We conducted a retrospective, descriptive study involving I 017 patients admitted to the Inkosi Albert Luthuli Central Hospital for treatment of CVD during 2005 - 2015. Patients were identified using the hospital's electronic administrative system. Demographics, inpatient length of stay, surgical procedures, and survival status at discharge were also obtained for each patient. Descriptive statistics were used to analyse the data.

Results: The median age of CVD patients was $\mathbf{5 0 . 0}$ years, and $50.4 \%$ were male. The median inpatient length of stay was 13.0 days. Surgery was performed in $38.8 \%$ of patients. The mortality rate was $22.5 \%$.

Conclusion: The resource burden that CVD places on tertiary healthcare services and the high mortality in afflicted patients highlights the need for effective primary and secondary prevention interventions in our setting. SAHeart 2021; | 8:56-61

Length of stay contributes to most of the costs associated with stroke care. One South African study reported that stroke care amounts to R2.5 - 4.2-million in some sub-districts, with inpatient length of stay accounting for a large proportion of these costs. ${ }^{(7)}$ Other aspects of CVD care, including medical, laboratory, and radiologic investigations, can also be very costly to the public health system. (7) Furthermore, CVD is associated with high levels of inpatient mortality at South African hospitals. An inpatient mortality rate of $16 \%$ - 33\% was reported at the GF Jooste Hospital in Cape Town, depending on whether the patients were admitted to general ward or a specialist stroke unit. ${ }^{(6)}$ A recent chart review of 136 stroke patients from a regional hospital in KwaZulu-Natal reported a lower, but still concerning inpatient mortality rate of $4 \% .{ }^{(8)}$

The consequences of CVD highlight the importance of preventative efforts across the disease continuum. Primary prevention seeks to reduce the future risk of disease in individuals who are free from sub-clinical/clinical disease through health promotion and other risk reduction activities. ${ }^{(9-1)}$ Secondary 
prevention seeks to timeously identify those who have subclinical disease and poorly controlled risk factors through screening processes. . $^{(-1)}$ In theory, individuals who are timeously screened and diagnosed with sub-clinical disease can be linked to treatment earlier, resulting in better clinical outcomes when compared with individuals who already demonstrate manifestations of clinical disease at the time of screening. Tertiary prevention applies to individuals who have clinical disease (i.e., those who have already suffered a stroke). The focus of tertiary prevention is effective management of existing clinical disease such that the risk of subsequent complications, including death, is greatly reduced. ${ }^{(9-1)}$ Tertiary prevention often requires specialist inpatient medical/surgical services (tertiary-level care), ${ }^{(11)}$ and is not offered at all hospitals in South Africa. ${ }^{(12)}$ Tertiarylevel care is also very costly, ${ }^{(13)}$ which is another important consideration in a resource-constrained country such as South Africa.

We sought to improve our understanding around the impact that CVD has on specialist services in our resource-constrained setting by conducting a descriptive study of inpatient admissions for CVD at a tertiary-level hospital in KwaZulu-Natal, South Africa.

\section{MATERIALS AND METHODS}

\section{Study design and setting}

This was a retrospective, descriptive study of inpatient data collected at the Inkosi Albert Central Hospital (IALCH) in Durban, KwaZulu-Natal. The province of KwaZulu-Natal is located on the east coast of South Africa and is administratively divided into II district municipalities: Amajuba, eThekwini (which includes the City of Durban), Harry Gwala, iLembe, King Cetshwayo, Ugu, Umgungundlovu (which includes the City of Pietermaritzburg), Umkhanyakude, Umzinyathi, Uthukela, and Zululand. IALCH is a tertiary-level, public-sector hospital in KwaZulu-Natal and offers medical and surgical services in most of the major clinical specialties. Admission to IALCH is referralbased, with most patients being referred from lower-level regional hospitals in the province.

\section{Study sample}

Our study sample consisted of I 017 adult patients who were admitted to $I A L C H$ for treatment of their CVD between I January 2005 and 3 I December 2015.

\section{Data collection}

All patients comprising our study sample were identified from the IALCH electronic administrative system using International
Classification of Diseases - Tenth Revision (ICD-10) primary diagnosis codes indicative of CVD (Table I).

TABLE I: ICD-I0 codes used to define CVD in this study.

\begin{tabular}{|c|c|}
\hline $\begin{array}{l}\text { ICD-10 } \\
\text { code }\end{array}$ & Description \\
\hline G45.0 & Vertebro-basilar artery syndrome \\
\hline G45.I & Carotid artery syndrome (hemispheric) \\
\hline G45.8 & $\begin{array}{l}\text { Other transient cerebral ischaemic attacks and related } \\
\text { syndromes }\end{array}$ \\
\hline G45.9 & Transient cerebral ischaemic attack, unspecified \\
\hline 160.0 & Subarachnoid haemorrhage from carotid siphon and bifurcation \\
\hline 160.1 & Subarachnoid haemorrhage from middle cerebral artery \\
\hline 160.2 & Subarachnoid haemorrhage from anterior communicating artery \\
\hline 160.3 & $\begin{array}{l}\text { Subarachnoid haemorrhage from posterior communicating } \\
\text { artery }\end{array}$ \\
\hline 160.4 & Subarachnoid haemorrhage from basilar artery \\
\hline 160.5 & Subarachnoid haemorrhage from vertebral artery \\
\hline 160.6 & Subarachnoid haemorrhage from other intracranial arteries \\
\hline 160.7 & Subarachnoid haemorrhage from intracranial artery, unspecified \\
\hline 160.8 & Other subarachnoid haemorrhage \\
\hline 160.9 & Subarachnoid haemorrhage, unspecified \\
\hline 161 & Intracerebral haemorrhage \\
\hline 161.0 & Intracerebral haemorrhage in hemisphere, subcortical \\
\hline 161.1 & Intracerebral haemorrhage in hemisphere, cortical \\
\hline 161.2 & Intracerebral haemorrhage in hemisphere, unspecified \\
\hline 161.3 & Intracerebral haemorrhage in brain stem \\
\hline 161.4 & Intracerebral haemorrhage in cerebellum \\
\hline 161.5 & Intracerebral haemorrhage, intraventricular \\
\hline 161.6 & Intracerebral haemorrhage, multiple localized \\
\hline 161.8 & Other intracerebral haemorrhage \\
\hline 161.9 & Intracerebral haemorrhage, unspecified \\
\hline 163.0 & Cerebral infarction due to thrombosis of precerebral arteries \\
\hline 163.2 & $\begin{array}{l}\text { Cerebral infarction due to unspecified occlusion or stenosis of } \\
\text { precerebral arteries }\end{array}$ \\
\hline 163.3 & Cerebral infarction due to thrombosis of cerebral arteries \\
\hline 163.4 & Cerebral infarction due to embolism of cerebral arteries \\
\hline 163.5 & $\begin{array}{l}\text { Cerebral infarction due to unspecified occlusion or stenosis of } \\
\text { cerebral arteries }\end{array}$ \\
\hline 163.8 & Other cerebral infarction \\
\hline 163.9 & Cerebral infarction, unspecified \\
\hline 164 & Stroke, not specified as haemorrhage or infarction \\
\hline
\end{tabular}


Other variables retrospectively extracted from the $\mathrm{IALCH}$ electronic administrative system for the purposes of our study included the patient's age, gender, length of inpatient stay, surgical procedures, and survival status at discharge. We deidentified the data extracted from the IALCH electronic administrative system and saved this as a Microsoft Excel ${ }^{\circledR}$ spreadsheet in preparation for the subsequent data analysis.

\section{Data analysis}

Descriptive statistics were used to summarise the characteristics of our study sample. We calculated medians and interquartile ranges for continuous variables, and frequencies and proportions for categorical variables. We performed the data analysis using $R$ version 3.6.2 (R Foundation for Statistical Computing, Vienna, Austria).

\section{Ethical approval}

Our study was part of a larger healthcare utilisation project at IALCH, which was approved by the Biomedical Research Ethics Committee at the University of KwaZulu-Natal (Protocol BE595/I6).

\section{RESULTS}

A description of our study sample is provided in Table II. The median age of our study sample was 50 years old, and there were similar proportions of males and females. The median length of stay was 13 days. There were 395 patients (38.8\%) who received surgical intervention. Of those patients who received surgical intervention, 232 (58.7\%) had neurosurgery, 126 (31.9\%) had vascular surgery, and 37 (9.4\%) had other surgical procedures. There was a particularly high inpatient mortality rate (229 patients, $22.5 \%$ ).

TABLE II: Description of the study sample ( $n=|0| 7)$.

\begin{tabular}{|c|c|}
\hline Characteristic & Summary statistic \\
\hline Age, median in years (interquartile range) & $50.0(39.0-61.0)$ \\
\hline \multicolumn{2}{|l|}{ Gender, $\mathrm{n}(\%$ of $\mathrm{n})$} \\
\hline Female & $504(49.6)$ \\
\hline Male & $513(50.4)$ \\
\hline $\begin{array}{l}\text { Length of inpatient stay, median in days } \\
\text { (interquartile range) }\end{array}$ & $13.0(8.0-21.0)$ \\
\hline \multicolumn{2}{|l|}{ Surgical intervention, $n$ (\% of $n$ ) } \\
\hline No & $622(61.2)$ \\
\hline Yes & $395(38.8)$ \\
\hline \multicolumn{2}{|l|}{ Died in hospital, $n$ (\% of $n$ ) } \\
\hline No & $788(77.5)$ \\
\hline Yes & $229(22.5)$ \\
\hline
\end{tabular}

TABLE III: CVD by ICD-I0 descriptions at IALCH, $2005-2015$.

\begin{tabular}{|c|c|}
\hline ICD-I 0 description & $\begin{array}{r}n(\% \text { of } \\
n=10\end{array}$ \\
\hline Vertebro-basilar artery syndrome & I $(0.1)$ \\
\hline Carotid artery syndrome (hemispheric) & $4(0.4)$ \\
\hline $\begin{array}{l}\text { Other transient cerebral ischaemic attacks and } \\
\text { related syndromes }\end{array}$ & $9(0.9)$ \\
\hline Transient cerebral ischaemic attack, unspecified & $33(3.2)$ \\
\hline $\begin{array}{l}\text { Subarachnoid haemorrhage from carotid siphon } \\
\text { and bifurcation }\end{array}$ & $4(0.4)$ \\
\hline $\begin{array}{l}\text { Subarachnoid haemorrhage from middle } \\
\text { cerebral artery }\end{array}$ & $16(1.6)$ \\
\hline $\begin{array}{l}\text { Subarachnoid haemorrhage from anterior } \\
\text { communicating artery }\end{array}$ & $36(3.5)$ \\
\hline $\begin{array}{l}\text { Subarachnoid haemorrhage from posterior } \\
\text { communicating artery }\end{array}$ & $34(3.3)$ \\
\hline Subarachnoid haemorrhage from basilar artery & $4(0.4)$ \\
\hline Subarachnoid haemorrhage from vertebral artery & $2(0.2)$ \\
\hline $\begin{array}{l}\text { Subarachnoid haemorrhage from other } \\
\text { intracranial arteries }\end{array}$ & $8(0.8)$ \\
\hline $\begin{array}{l}\text { Subarachnoid haemorrhage from intracranial } \\
\text { artery, unspecified }\end{array}$ & $17(1.7)$ \\
\hline Other subarachnoid haemorrhage & $26(2.6)$ \\
\hline Subarachnoid haemorrhage, unspecified & $203(20.0)$ \\
\hline Intracerebral haemorrhage & I $(0.1)$ \\
\hline Intracerebral haemorrhage in hemisphere, subcortical & $9(0.9)$ \\
\hline Intracerebral haemorrhage in hemisphere, cortical & $2(0.2)$ \\
\hline Intracerebral haemorrhage in hemisphere, unspecified & $7(0.7)$ \\
\hline Intracerebral haemorrhage in brain stem & $7(0.7)$ \\
\hline Intracerebral haemorrhage in cerebellum & $10(1.0)$ \\
\hline Intracerebral haemorrhage, intraventricular & $140(13.8)$ \\
\hline Intracerebral haemorrhage, multiple localized & $3(0.3)$ \\
\hline Other intracerebral haemorrhage & $53(5.2)$ \\
\hline Intracerebral haemorrhage, unspecified & $107(10.5)$ \\
\hline $\begin{array}{l}\text { Cerebral infarction due to thrombosis of } \\
\text { precerebral arteries }\end{array}$ & I $(0.1)$ \\
\hline $\begin{array}{l}\text { Cerebral infarction due to unspecified occlusion or } \\
\text { stenosis of precerebral arteries }\end{array}$ & $2(0.2)$ \\
\hline $\begin{array}{l}\text { Cerebral infarction due to thrombosis of } \\
\text { cerebral arteries }\end{array}$ & $4(0.4)$ \\
\hline $\begin{array}{l}\text { Cerebral infarction due to embolism of } \\
\text { cerebral arteries }\end{array}$ & I $(0.1)$ \\
\hline $\begin{array}{l}\text { Cerebral infarction due to unspecified occlusion or } \\
\text { stenosis of cerebral arteries }\end{array}$ & $14(1.4)$ \\
\hline Other cerebral infarction & $57(5.6)$ \\
\hline Cerebral infarction, unspecified & $89(8.8)$ \\
\hline Stroke, not specified as haemorrhage or infarction & $113(11.1)$ \\
\hline
\end{tabular}


The three most common categories of CVD based on ICD- I0 code descriptions (Table III) were "Subarachnoid haemorrhage, unspecified" (203 patients, 20.0\%), "Intracerebral haemorrhage, intraventricular" (140 patients, 13.8\%), and "Stroke, not specified as haemorrhage or infarction" (113 patients, ।. $1 \%)$.

\section{DISCUSSION}

The 2 most important findings from our study of CVD admissions at a tertiary South African hospital were the duration of the inpatient length of stay (Median of 13.0 days) and the high mortality rate (22.5\%). Our findings for patient age and gender are similar to those reported in other hospital-based studies of CVA in South Africa. ${ }^{(14)}$ Our findings for the surgical intervention rate are to be expected, considering that patients attending a tertiary level hospital often have complex, advanced disease which cannot be managed solely through medical (nonsurgical) therapy alone.

The inpatient length of stay observed in our study ( 13.0 days) was outside the range reported in a prior study of CVA admissions at the regional-level GF Jooste Hospital in Cape Town (range: 6.4 - 10.4 days). ${ }^{(6)}$ The difference in observed inpatient length of stay between the 2 studies is likely due to the difference in patient profiles between tertiary and regional-level hospitals. Patients attending tertiary level facilities are more likely to have severe, complex disease than those attending lower-level facilities, which would require these complex cases to stay longer in hospital for specialist medical or surgical procedures and their subsequent rehabilitation. However, this can equate to a considerable financial burden that the South African public healthcare system must incur, if the cost of inpatient length of stay at a tertiary-level hospital is considered. Therefore, from the point-of-view of the public healthcare sector, there is a clear financial incentive for effective primary and secondary prevention interventions addressing CVD in the general South African population.

Although the mortality rate reported in our study (22.5\%) was within the range reported in other hospital-based studies of CVD in South Africa (range: $4 \%-33 \%)^{(6,8)}$ it is still alarmingly high. We attribute this high mortality rate to patient-related delays in presentation for care and poorly controlled CVD risk factors in the general population. Patient-related delays in presenting to a hospital following a CVD event can impact the effectiveness of current treatments or the eligibility of patients for these treatments. ${ }^{(8,15)}$ A recent study conducted at the emergency department of a tertiary academic hospital in Johannesburg found that only $18.7 \%$ of CVD patients presented to hospital within the 4.5 hour therapeutic window for thrombolysis. ${ }^{(15)}$ Unsurprisingly, clinical outcomes are far worse in patients who delay seeking healthcare for CVD when compared with patients who timeously present to a healthcare facility. While it might not be the only reason for patient-related delays in seeking healthcare for CVD, poor knowledge and awareness of this condition in the general population is by far the most commonly cited reason. ${ }^{(15)}$ There is poor knowledge and awareness of cardiovascular conditions, including heart disease and CVD, among the general South African population. ${ }^{(16)} \mathrm{A}$ clear understanding of CVD signs and symptoms would enable the condition to be recognised by afflicted patients or their families at an early stage. This would then facilitate timeous presentation to a healthcare facility, and hopefully a better clinical outcome for the afflicted patient. Therefore, improving knowledge and awareness around CVD signs and symptoms in the general South African population through well-designed primary prevention interventions should be made a priority by public health specialists. Suboptimal control of CVD risk factors can also impact long-term patient outcomes. If left untreated for an extended period of time, CVD risk factors such as hypertension cause progressive damage which can lead to more severe CVD and a higher likelihood of significant morbidity or mortality. ${ }^{(17)}$ The preponderance of patients with haemorrhagic CVD in our study points to hypertension being an important CVD risk factor in our South African setting. ${ }^{(18)}$ Communitybased screening for hypertension in South Africa is well accepted, but challenges exist in linking newly diagnosed patients to treatment at healthcare facilities. A study of a community-based screening intervention conducted in rural KwaZulu-Natal found that only $26.9 \%$ of individuals diagnosed with hypertension accessed treatment within 2 years following their diagnosis. ${ }^{(19)}$ Even when patients do access care, there is an additional challenge of ensuring optimal control of the CVD risk factor through treatment adherence. Adherence to hypertensive medications in the general South African population is poor. (20) One way to address the challenge of breakdowns in linkage to care for individuals with CVD risk factors and improving treatment adherence is using community-based, peer-led interventions. Community healthcare workers have already been used in South Africa with great success to improve linkage to care and treatment adherence in persons with HIV infection, (21-23) and it is likely that a similar approach for CVD risk factors would improve secondary prevention for CVD and associated clinical outcomes in our setting. 
Our study was not without limitations. We analysed patient data collected at a single tertiary hospital, and our findings might not be generalisable to other hospitals in South Africa. We also identified patients with CVD based on the primary ICD-IO diagnosis code listed for their admission, and there might have been some patients who were incorrectly coded as having CVD on the IALCH electronic administrative system. However, this is likely to be a small proportion of patients as our ICD- I0 coding department consistently reports its coding accuracy at 90\% - 95\%. Lastly, we were unable to provide a report on patient comorbidities/risk factors for CVD and post-discharge mortality, as this data is not included in the IALCH electronic administrative system.
In conclusion, our study provides an insight on the resource burden that CVD places on tertiary healthcare services in South Africa. We also found an alarmingly high mortality rate in patients admitted for treatment of CVD. Our research highlights the need for effective primary and secondary prevention interventions for CVD in our setting.

\section{Conflict of interest: none declared.}

\section{MULTIPLE CHOICE QUESTIONS}

\section{Primary prevention seeks to:}

A. Effectively manage existing clinical disease such that the risk of subsequent complications is greatly reduced.

B. Reduce the future risk of disease in individuals who are free from sub-clinical/clinical disease through health promotion.

C. Identify those who have sub-clinical disease and poorly controlled risk factors through screening processes.

D. All of the above.

\section{Secondary prevention seeks to:}

A. Identify those who have sub-clinical disease and poorly controlled risk factors through screening processes.

B. Reduce the future risk of disease in individuals who are free from sub-clinical/clinical disease through health promotion.

C. Effectively manage existing clinical disease such that the risk of subsequent complications is greatly reduced.

D. None of the above.

\section{Tertiary-level care is:}

A. Costly.

B. Usually involves specialist medical or surgical services.

C. Often centralised at certain public hospitals.

D. All of the above. 
I. American Association of Neurological Surgeons. (2020). Cerebrovascular disease. Retrived November 24, 2020, from https://www.aans.org/Patients/ Neurosurgical-Conditions-and-Treatments/Cerebrovascular-Disease.

2. Feigin $\mathrm{VL}$, Forouzanfar $\mathrm{MH}$, Krishnamurthi $\mathrm{R}$, et al. Global and regional burden of stroke during 1990 - 2010: Findings from the Global Burden of Disease Study 2010. Lancet 2014;383:245-254.

3. Pillay-van Wyk V, Msemburi W, Laubscher R, et al. Mortality trends and differentials in South Africa from 1997 - 2012: Second National Burden of Disease Study. Lancet Glob Health 2016;4:e642-653.

4. Rayner B. Hypertension: Detection and management in South Africa. Nephron Clin Pract 20 I 0; 1 16:c269-273.

5. Mayosi BM, Flisher AJ, Lalloo UG, et al. The burden of non-communicable diseases in South Africa. Lancet 2009;374:934-947.

6. De Villiers L, Kalula SZ, Burch VC. Does multidisciplinary stroke care improve outcome in a secondary-level hospital in South Africa? International Journal of Stroke 2009;4:89-93.

7. Maredza M, Chola L. Economic burden of stroke in a rural South African setting. eNeurologicalSci 2016;3:26-32.

8. Feris SG, Naicker B. Acute stroke in the emergency department: A chart review at KwaZulu-Natal hospital. S Afr Fam Pract 2020;62:a5 I 26.

9. Karunathilake SP, Ganegoda GU. Secondary prevention of cardiovascular diseases and application of technology for early diagnosis. Biomed Res Int 20।8;2018:5767864.

10. Baumann LC, Karel A. Prevention: Primary, Secondary, Tertiary. In: Gellman MD, Turner JR (eds). Encyclopedia of Behavioral Medicine. New York, NY: Springer New York; 20 I3: I532- 1534.

II. Dobe M. Health promotion for prevention and control of non-communicable diseases: unfinished agenda. Indian J Public Health 20 I2;56: I 80- 186.

12. Dell AJ, Kahn D. Geographical maldistribution of surgical resources in South Africa: A review of the number of hospitals, hospital beds and surgical beds. S Afr Med J 2017; 107:1099-1 105.

13. Ramjee S. (20।3). Comparing the Cost of Delivering Hospital Services across the Public and Private Sectors in South Africa. Retrived November 24, 2020, from https://www.insight.co.za/wp-content/uploads/20 15/07/Comparing-thecost-of-hospitalisation-across-the-public-and-private-sectors-in-South-AfricaOctober-24.pdf

14. Connor MD, Modi G, Warlow CP. Differences in the nature of stroke in a multiethnic urban South African population: The Johannesburg hospital stroke register. Stroke 2009;40:355-62.

15. Khalema D, Goldstein LN, Lucas S. A retrospective analysis of time delays in patients presenting with stroke to an academic emergency department. SA Journal of Radiology 2018;22:al 319.

16. Tibazarwa K, Ntyintyane L, Sliwa K, et al. A time bomb of cardiovascular risk factors in South Africa: results from the Heart of Soweto Study "Heart Awareness Days". Int J Cardiol 2009; I 32:233-9.

17. Arboix A. Cardiovascular risk factors for acute stroke: Risk profiles in the different subtypes of ischemic stroke. World J Clin Cases 20I5;3:4 I8-29.

18. Ben Husein M, Le Feuvre D. Intracranial haemorrhage. CME 2013; 31:102-106.

19. Siedner MJ, Baisley K, Orne-Gliemann J, et al. Linkage to primary care after home-based blood pressure screening in rural KwaZulu-Natal, South Africa: A population-based cohort study. BMJ Open 2018;8:e023369.

20. Rampamba EM, Meyer JC, Godman B, Kurdi A, Helberg E. Evaluation of antihypertensive adherence and its determinants at primary healthcare facilities in rural South Africa. J Comp Eff Res 2018;7:661-672.

21. Katz IT, Bogart LM, Fitzmaurice GM, et al. The Treatment Ambassador Programme: A highly acceptable and feasible community-based peer intervention for South Africans living with HIV who delay or discontinue antiretroviral Therapy. AIDS Behav 2021;25:1।29-1।43.

22. Genberg BL, Shangani S, Sabatino K, et al. Improving engagement in the HIV care cascade: A systematic review of interventions involving people living with HIVIAIDS as peers. AIDS and Behavior 2016;20:2452-63.

23. Wilkinson, L. ART adherence clubs: A long-term retention strategy for clinically stable patients receiving antiretroviral therapy. Southern African Journal of HIV Medicine 20।3; 14:48-50. 